Daniela Batalha Trettel ${ }^{1}$

Juliana Ferreira Kozan ${ }^{1}$

Mario César Scheffer ${ }^{1}$

\title{
JUDICIALIZAÇÃO EM PLANOS DE SAÚDE COLETIVOS: OS EFEITOS DA OPÇÃO REGULATÓRIA DA AGÊNCIA NACIONAL DE SAÚDE SUPLEMENTAR NOS CONFLITOS ENTRE CONSUMIDORES E OPERADORAS
}

Judicialization of collective health insurance plans: The effects of the Brazilian National Regulatory Agency for Private Health Insurance and Plans regulatory choice in conflicts between consumers and private health insurance providers

${ }^{1}$ Universidade de São Paulo. São Paulo/SP, Brasil.

Correspondência: Daniela Batalha Trettel. E-mail: danielabtrettel@yahoo.com.br

Recebido em: 15/06/2017. Revisado: 04/09/2017. Aprovado: 18/09/2017 


\section{RESUMO}

Este estudo aborda a judicialização na saúde suplementar por meio da análise de ações judiciais contidas na base pública on-line do Tribunal de Justiça do Estado de São Paulo. Com a aplicação de formulário, foram analisadas 4.059 ações relacionadas a contratos coletivos de planos de saúde, ajuizadas no Município de São Paulo nos anos de 2013 e 2014. Além de quantificar e descrever o perfil das demandas levadas à Justiça, buscou-se a análise qualitativa de decisões judiciais. O estudo identificou que os principais problemas judicializados são exclusão de coberturas, manutenção do aposentado no contrato coletivo e reajuste de mensalidade de idosos por mudança de faixa etária e por aumento de sinistralidade. Conclui-se que a regulação e a jurisprudência são desarmônicas, apresentando-se sugestões de mudanças regulatórias necessárias para diminuição de conflitos que permeiam o mercado de planos e seguros de saúde.

\section{Palavras-Chave}

Jurisprudência; Plano de Saúde; Regulação; Saúde Suplementar.

\section{ABSTRACT}

This study aims to approach judicialization in private health insurance through the analysis of lawsuits contained in the public online database of the Court of Justice of the State of São Paulo. Through the application of a form, 4,059 lawsuits were analyzed, all related to collective contracts of private health insurance, filed in the city of São Paulo during 2013 and 2014. Besides of quantifying and describing the profile of the demands brought to justice, a qualitative analysis of judicial decisions was performed. The study identified the main issues judicialialized as coverage reductions, the maintenance of members of collective contracts even after retirement, and increases in monthly payments for members as they become older and charges for increased risk. Concluding that regulations and jurisprudence are discordant, the study suggests regulatory changes aiming at the reduction of conflicts that permeate the private health insurance market.

\section{Keywords}

Health Insurance; Jurisprudence; Regulation; Supplementary Health. 


\section{Introdução}

A judicialização consiste no movimento crescente de cidadãos que buscam o direito à saúde junto aos órgãos da justiça, e se insere em um fenômeno jurídico, político e sociológico ainda mais complexo de judicialização de políticas públicas, em especial das relacionadas à efetivação de direitos sociais ${ }^{1}$. Esse movimento é extremamente atual e mobiliza, para sua compreensão, a atuação de pesquisadores, gestores e membros dos diversos órgãos no âmbito do Poder Judiciário e do Ministério Público.

Dentre as dimensões possíveis de análise do fenômeno da judicialização, estão o estudo do comportamento da Justiça, da conformidade das decisões com a legislação, das competências das instituições reclamadas nos tribunais, das características dos autores das ações, dos perfis das demandas e dos problemas de saúde, bem como a análise das falhas e disfunções da regulação do sistema de saúde.

A maioria das pesquisas sobre judicialização da saúde concentra-se no estudo do fenômeno no âmbito do Sistema Único de Saúde (SUS)².

Porém, diante da posição dos planos de saúde no sistema de saúde brasileiro (eles assistem mais de um quarto da população) e da constatação de que esse mercado guarda com o sistema público uma relação simbiótica ${ }^{3}$, são fundamentais estudos que analisem o setor.

\footnotetext{
${ }^{1}$ VIANNA, L. W.k et al. A judicialização da política e das relações sociais no Brasil. 2. ed. Rio de Janeiro: Revan, 2014. ${ }^{2}$ v.g. ANDRADE, E. I. G. et al. A judicialização da saúde e a Política Nacional de Assistência Farmacêutica no Brasil: gestão da clínica e medicalização da justiça. Revista Médica de Minas Gerais, Belo Horizonte, v. 18, n. 4, Supl. 4, p. S46-S50, 2008. Disponível em: <http://rmmg.org/artigo/detalhes/1268>; CHIEFFI, A. L.; BARATA, R. B. Judicialização da política pública de assistência farmacêutica e equidade. Cadernos de Saúde Pública, Rio de Janeiro, v. 25, n.8, p.1839-1349, ago. 2009. Disponível em: <http://www.scielo.br/pdf/csp/v25n8/20.pdf>. http://dx.doi.org/10.1590/S0102-311X2009000800020; MARQUES, S. B.; DALLARI, S. G. Garantia do direito social à assistência farmacêutica no Estado de São Paulo. Revista Saúde Pública, São Paulo, v. 41, n. 1, p. 101107, fev. 2007. Disponível em: <http://www.revistas.usp.br/rsp/article/viewFile/32199/34304>; PEPE, V. L. E.; VENTURA, M. (Orgs.). Manual indicadores de avaliação e monitoramento das demandas judiciais de medicamentos. Rio de Janeiro: Fundação Oswaldo Cruz, Escola Nacional de Saúde Pública Sergio Arouca, 2011. Disponível em: <http://www5.ensp.fiocruz.br/biblioteca/dados/txt_975659982.pdf>; PEPE, V. L. E.; FIGUEIREDO, T. A.; SIMAS, L.; OSORIO-DE-CASTRO, C. G. S.; VENTURA, M. A judicialização da saúde e os novos desafios da gestão da assistência farmacêutica. Ciência \& Saúde Coletiva, Rio de Janeiro, v. 15, n. 5, p. 2405-2414, ago. 2010. Disponível em: <http:// www.scielo.br/pdf/csc/v15n5/v15n5a15.pdf>. http://dx.doi.org/10.1590/S1413-81232010000500015; TERRAZAS, F.V. O Poder Judiciário como voz institucional dos pobres: o caso das demandas judiciais por medicamentos. 2008. Dissertação (Mestrado em Direito) - Programa de Pós-Graduação em Direito, Faculdade de Direito. Universidade de São Paulo, São Paulo, 2008; WANG, D. W. L.; VASCONCELOS, N. P. de; OLIVEIRA, V. E. de; TERRAZAS, F.V. Os impactos da judicialização da saúde no município de São Paulo: gasto público e organização federativa. Revista de Administração Pública, Rio de Janeiro, v. 48, n. 5, p. 1191-1206, set./out. 2014. Disponível em: <http://www.scielo.br/pdf/rap/v48n5/06.pdf>. http://dx.doi.org/10.1590/0034-76121666.

${ }^{3}$ BAHIA, L. Mudanças e padrões das relações público-privado: seguros e planos de saúde no Brasil. 1999. Tese (Doutorado em Saúde Pública) - Faculdade de Medicina, Universidade Federal do Rio de Janeiro, 1999; TRETTEL, D. B. Planos de saúde na visão do STJ e do STF. São Paulo: Verbatim, 2010; SANTOS, I. S. Evidência sobre o mix público-privado em países com cobertura duplicada: agravamento das iniquidades e da segmentação em sistemas nacionais de saúde. Ciência \& Saúde Coletiva, Rio de Janeiro, v. 16, n. 6, p. 2.743-2.752, 2011. Disponível em: <http:// www.scielo.br/pdf/csc/v16n6/13.pdf>. http://dx.doi.org/10.1590/S1413-81232011000600013; TRETTEL, D.B. Planos de saúde e envelhecimento populacional: um modelo viável? 2015. Tese (Doutorado em Direito) - Programa de Pós-Graduação em Direito, Faculdade de Direito. Universidade de São Paulo, São Paulo, 2015.
} 
Plano de saúde, nos termos do artigo $1^{\circ}$ da Lei n. 9.656/1998 ${ }^{4}$ (Lei dos Planos de Saúde), é uma prestação de serviço continuada ou a cobertura de custos assistenciais, sem prazo determinado, cujo objetivo é garantir a assistência à saúde do contratante sem limitação financeira, incluindo ou não dependentes. Tal assistência à saúde pode abranger assistências médica, hospitalar e odontológica, combinadas ou não, podendo-se permitir a livre escolha do prestador de serviço e/ou oferecer acesso a uma rede credenciada ou referenciada. O pagamento de todas as despesas é integral ou parcialmente responsabilidade da operadora de planos de saúde, e se dá mediante reembolso ou pagamento direto ao prestador de serviço que atendeu ao usuário.

A regulamentação do mercado de planos de saúde ocorreu apenas em 1998, quando publicada a Lei n. 9.656. E, em 2000, criou-se agência reguladora específica para cuidar do setor de planos de saúde, a Agência Nacional de Saúde Suplementar (ANS), por meio da Lei n. 9.9615

Desde o início, a atuação regulatória dessa agência apresenta problemas, omitindo ou mesmo ratificando práticas abusivas cometidas pelas operadoras, que acabariam por ecoar no Poder Judiciário ${ }^{6}$. Assim, mesmo regulamentado e regulado, o setor de planos de saúde ainda é muito conflituoso. As demandas judiciais aumentam ano a ano e se concentram principalmente em questões relacionadas a coberturas e reajustes ${ }^{7}$.

Os planos de assistência médico-hospitalar são atualmente responsáveis pela atenção à saúde de 47,7 milhões de pessoas ${ }^{8}$, o que corresponde a $26,6 \%$ da população do país. O número de pessoas vinculadas ao setor apresentou crescimento desde que a ANS foi criada, mas em momentos de crise econômica há retração, sobretudo dos contratos coletivos em função do desemprego.

Os planos coletivos são aqueles contratados com a intermediação de uma pessoa jurídica, empresa empregadora, associação ou sindicato relacionado a categorias profissionais. Abrigam 38,1 milhões de pessoas ${ }^{9}$, praticamente $80 \%$ de todos os usuários de planos de saúde, e foram os que tiveram maior crescimento

\footnotetext{
${ }^{4}$ BRASIL. Lei n. 9656, de 03 de junho de 1988. Dispõe sobre os planos e seguros privados de assistência à saúde. Disponível em: <http://www.planalto.gov.br/ccivil_03/Leis/L9656compilado.htm>. Acesso em: 17 jun. 2018.

${ }^{5}$ BRASIL. Lei 9.961, de 28 de janeiro de 2000. Cria a Agência Nacional de Saúde Suplementar - ANS e dá outras providências. Disponível em: <http://www.planalto.gov.br/ccivil_03/Leis/L9961.htm>. Acesso em: 17 jun. 2018.

${ }^{6}$ SALAZAR, A. L.; RODRIGUES, K.; NUNES JÚNIOR, V. S. A assistência privada à saúde: regulamentação, posição IDEC e reflexos no sistema público. In: ARANHA, Márcio lorio (Org.). Direito sanitário e saúde pública. Brasília, 2003. v. 1, p. 333-362.

${ }^{7}$ TRETTEL, D. B. Planos de saúde na visão do STJ e do STF, cit.

${ }^{8}$ BRASIL. Ministério da Saúde. ANS. Caderno de Informação da Saúde Suplementar: Beneficiários, Operadoras e Planos, dez. 2016. Rio de Janeiro: ANS, 2017.

${ }^{9}$ d. Ibid.
} 
na última década. De 2006 a 2016, a quantidade de usuários dessa modalidade de contratação identificados pela ANS aumentou de 25,8 milhões ${ }^{10}$ para 38,1 milhões, ou seja, houve um aumento de 12,3 milhões de pessoas. No mesmo período, os beneficiários de contratos individuais ou familiares - que são contratados diretamente pelo usuário junto à operadora, sem a presença de um intermediário entre ambos - saltaram de 8,2 milhões ${ }^{11}$ para 9,3 milhões ${ }^{12}$ - um acréscimo bastante inferior, de 1,1 milhão de pessoas.

Tal fenômeno de crescimento vertiginoso da contratação de planos coletivos é chamado de "coletivização". Pode ser explicado pelo fato de os planos de saúde individuais possuírem uma proteção legal maior no que se refere à aplicação de reajustes e ao cancelamento unilateral, bem como pela branda regulamentação dos planos coletivos.

A coletivização dos planos de saúde já emana efeitos também na judicialização. Além das exclusões e negativas de coberturas assistenciais, conflitos próprios dos contratos coletivos chegam cada vez mais ao Poder Judiciário, como problemas relacionados a reajustes, cancelamento unilateral de contrato e manutenção de ex-empregados no plano. O estudo descrito a seguir visa justamente a compreender o fenômeno da judicialização dos planos coletivos e apontar subsídios para se discutirem as práticas desse mercado e a regulação setorial.

\section{Metodologia}

Trata-se de estudo que visa a abordar a judicialização na saúde suplementar por meio da análise de ações judiciais contidas na base pública online do Tribunal de Justiça do Estado de São Paulo (TJSP). Além de quantificar e descrever o perfil das demandas levadas à Justiça, buscou-se construir uma série de análises, entre elas as que demonstram eventuais lacunas legislativas ou regulatórias - que serão apresentadas no presente trabalho.

A escolha da abrangência geográfica da pesquisa, restrita ao Estado de São Paulo, justificou-se por ser esta a unidade da Federação que concentra a maior taxa de cobertura de saúde suplementar: à época da coleta de dados, $44,8 \%$ da população do estado (18,4 milhões de usuários) estava vinculada a planos e seguros de saúde ${ }^{13}$.

A análise das decisões judiciais do TJSP deve-se ao fato de este ser o responsável por julgar os recursos das ações judiciais envolvendo planos e seguros de

\footnotetext{
${ }^{10}$ BRASIL. Ministério da Saúde. ANS. Caderno de Informação da Saúde Suplementar: Beneficiários, Operadoras e Planos, dez. 2006. Rio de Janeiro: ANS, 2007.

${ }^{11}$ ld. Ibid.

${ }^{12}$ BRASIL. Ministério da Saúde. ANS. Caderno de Informação da Saúde Suplementar: Beneficiários, Operadoras e Planos, dez. 2016, cit.

${ }^{13}$ BRASIL. Ministério da Saúde. ANS. Caderno de Informação da Saúde Suplementar: Beneficiários, Operadoras e Planos, set. 2014. Rio de Janeiro: ANS, 2014.
} 
saúde. No âmbito do estado, trata-se da instância judicial que por último se manifesta sobre os conflitos envolvendo usuários e operadoras de planos de saúde. Por barreiras - entraves criados para a admissibilidade de recursos - impostas pela lei e pelo próprio Poder Judiciário ${ }^{14},{ }^{15}$, raros casos voltam a ser analisados por instâncias superiores (Superior Tribunal de Justiça e Supremo Tribunal Federal), sendo os tribunais de justiça os locais mais profícuos para compreender o fenômeno da judicialização dos planos de saúde.

As decisões selecionadas são de caráter definitivo (apelação e embargos infringentes ${ }^{16}$ ), descartando-se aquelas referentes a liminares e/ou antecipação de tutela devido a seu caráter provisório. Tal tribunal, em seu sistema de indexação, permite selecionar com precisão os conflitos relacionados a planos de saúde ${ }^{17}$.

Temporalmente, a pesquisa considerou os julgados dos anos de $2013 \mathrm{e}$ 2014. Como a pesquisa teve sua coleta de dados em 2015, tais anos representavam os dois últimos com repositório completo passível de análise. Apenas nesses dois anos, o TJSP julgou quase 20 mil casos relacionados ao corte da pesquisa. Para viabilizar uma análise depurada das decisões, novo corte metodológico foi realizado: foram lidas todas as decisões que envolviam conflitos entre usuários de planos de saúde coletivos ${ }^{18}$ e operadoras no Município de São Paulo, totalizando 4.059 casos, aos quais se aplicou questionário estruturado mediante leitura completa dos acórdãos por uma equipe de pesquisadores, o que gerou o banco de dados do estudo.

O estudo foi aprovado pelo Comitê de Ética em Pesquisa da Faculdade de Medicina da Universidade de São Paulo (FMUSP) ${ }^{19}$.

\footnotetext{
${ }^{14}$ As súmulas do Superior Tribunal de Justiça n. 5 (“A simples interpretação de cláusula contratual não enseja Recurso Especial”) e n. 7 (“A pretensão de simples reexame de prova não enseja Recurso Especial”) servem de fundamento para barrar a subida de recursos a essa instância superior nos temas tratados nas decisões analisadas.

${ }^{15}$ PEIXOTO, G. C. C. C.; SILVA, N. M. E. O acesso à justiça e os entraves jurisprudenciais criados para admissão do recurso especial. 2013. In: SOCIEDADE global e seus impactos sobre o estudo e a efetividade do direito na contemporaneidade. Florianópolis: FUNJAB, 2013. v. 1, p. 343-358.

${ }^{16}$ Nos casos em que o acórdão foi proferido no julgamento de embargos infringentes, foi necessário identificar se havia, entre as decisões selecionadas, o acórdão da apelação correspondente ao mesmo processo e retirá-la do banco de dados. Caso contrário, no banco haveria duplicidade de acórdãos referentes à mesma demanda.

${ }^{17}$ O sistema de armazenamento de jurisprudência do TJSP tem sua própria indexação, chamada SAJ (https:// esaj.tjsp.jus.br/cjsg/consultaCompleta.do). No que se refere ao filtro relacionado ao assunto, os conflitos entre usuários de planos de saúde e operadoras são indexados como "planos de saúde" (código 6233), dentro do tópico "contratos de consumo", e como "cobrança de seguro saúde" (código 10000629), "material rel plano/seg saude/conv saúde" (código 10000983), "plano de saúde" (código 10001132) e "seguro saúde" (código 10001318), dentro do tópico "assuntos do antigo SAJ". Todos esses assuntos foram considerados na busca.

${ }^{18} \mathrm{Com}$ o objetivo de filtrar as decisões que tratavam de planos de saúde contratados coletivamente, no campo de "pesquisa livre" do sistema de busca, foram inseridos os termos "coletivo", "empresarial" e "adesão", intercalados pelo conector "ou".

${ }^{19}$ CAAE: 33007014.9.0000.0065.
} 


\section{Resultados e discussão}

Os resultados da pesquisa foram obtidos com base na análise de decisões proferidas nas ações judiciais que discutem conflitos entre consumidores e planos de saúde na cidade de São Paulo.

Cumpre esclarecer que os conflitos entre consumidores e operadoras de planos de saúde chegam à Justiça quando não foi possível chegar a um acordo em uma negociação extrajudicial, direta ou com a intermediação de órgãos de defesa do consumidor, como os Procon, e da própria ANS, ou ainda quando a urgência do caso requer uma intervenção rápida do Poder Judiciário, por meio de avaliação e concessão de decisões liminares, como nos casos de negativas de cobertura de tratamento.

\section{A predominância de decisões favoráveis aos usuários}

O estudo verificou o resultado da demanda, ou seja, se a decisão analisada foi favorável, parcialmente favorável ou desfavorável ao usuário de plano de saúde.

A análise não levou em consideração discussões meramente processuais ou pedidos exclusivamente de danos morais, mas sim se o bem da vida requerido (como a revisão do reajuste e a cobertura do procedimento negado, entre outros) foi ou não concedido ao usuário.

Constata-se que quase a totalidade das decisões analisadas foram favoráveis aos consumidores de planos de saúde: em 92,4\% dos acórdãos foi dada razão ao consumidor, sendo que $88 \%$ o consumidor teve sua pretensão integralmente acolhida e em outros 4,4\% sua pretensão foi acolhida em parte; e em apenas 7,4\% dos recursos julgados a operadora de plano de saúde logrou êxito (Tabela 1).

Tabela 1. Resultado do julgamento na Comarca de São Paulo do TJSP, referentes a contratos de planos de saúde coletivos, 2013 e 2014

\begin{tabular}{lrr}
\hline Resultado da demanda & \multicolumn{1}{c}{ Total } & \multicolumn{1}{c}{$\%$} \\
\hline Decisão favorável ao usuário & 3.575 & 88,08 \\
Decisão desfavorável ao usuário & 300 & 7,39 \\
Decisão parcialmente favorável ao usuário & 174 & 4,29 \\
Demanda entre operadora e empresa contratante & 10 & 0,25 \\
\hline
\end{tabular}

O altíssimo percentual de ações favoráveis ao pleito dos consumidores e pacientes chama atenção para o descompasso entre a interpretação dada à legislação brasileira pelas operadoras de planos de saúde e pela ANS em relação aos tribunais, gerando alta conflituosidade. 
Um ponto que merece destaque se relaciona à desconsideração das normas de defesa do consumidor pelos agentes reguladores e empresariais do mercado de planos de saúde: o Poder Judiciário, ao julgar, acaba por "lembrá-los" de que as normas e preceitos gerais do Código de Defesa do Consumidor, do Código Civil e da Constituição Federal também se aplicam ao setor, não havendo eficácia regulatória no foco dado pela ANS apenas na Lei n. 9.656/1998 e nas normas expedidas por ela mesma.

A pesquisa também catalogou a legislação utilizada na fundamentação da decisão judicial. Analisando este dado, constatou-se que as legislações mais utilizadas como fundamento para decidir as demandas analisadas são o Código de Defesa do Consumidor, citado em 56,8\% das decisões (2.305 acórdãos), e a Lei n. 9.656/1998, evocada em 56,6\% decisões (2.297 acórdãos).

O Código de Defesa do Consumidor é norma de ordem pública e interesse social, que se apresenta como importante instrumento de promoção de justiça e de igualdade material ao equilibrar a relação entre consumidores e fornecedores.

Nessa linha, o Superior Tribunal de Justiça (STJ) editou a Súmula n. 469, com a seguinte redação: "Aplica-se o Código de Defesa do Consumidor aos contratos de plano de saúde". A súmula consolida o entendimento já pacificado no STJ e nos demais tribunais do país, no sentido de que a operadora de plano de saúde que presta serviços remunerados de assistência à saúde à população tem sua atividade regida pelo Código de Defesa do Consumidor.

Assim, a Lei n. 9.656/1998 e o Código de Defesa do Consumidor podem e devem ser aplicados concomitantemente às demandas que discutem questões de planos de saúde, buscando sempre harmonizar as disposições destas duas legislações.

Portanto, falha a regulação exercida pela ANS quando, com base em interpretação equivocada da legislação, deixa de aplicar as normas protetivas do Código de Defesa do Consumidor, voltando-se mais aos interesses das operadoras e à viabilidade do mercado de planos de saúde e menos às necessidades do consumidor e à garantia do direito à saúde, ou ainda à fiscalização do mercado e efetiva penalização das operadoras.

\section{A exclusão de coberturas}

O tema mais recorrente nas demandas, que foi discutido em $48 \%$ das decisões analisadas (1.935 decisões tratam do tema), é a exclusão de cobertura (Tabela 2), casos em que um procedimento é solicitado pelo médico que acompanha o paciente, mas a operadora se recusa a oferecer cobertura. 
Tabela 2. Assuntos discutidos nas decisões judiciais na Comarca de São Paulo do TJSP referentes a contratos de planos de saúde coletivos, 2013 e 2014

\begin{tabular}{lrr}
\hline Assunto & Total & \multicolumn{1}{c}{$\%$} \\
\hline Exclusão de cobertura & 1.935 & 47,67 \\
Contrato coletivo e aposentadoria: discussão do valor da mensalidade & 608 & 14,98 \\
Manutenção do aposentado no contrato coletivo (art. 31, Lei n. 9.656/1998) & 589 & 14,51 \\
Reajuste por mudança de faixa etária & 475 & 11,70 \\
Reajuste por aumento de sinistralidade & 275 & 6,78 \\
\hline
\end{tabular}

A Lei n. 9.656/1998, em seu artigo 10, garante aos consumidores contratantes de planos de saúde a cobertura de todas as patologias listadas pela Organização Mundial da Saúde (OMS). Segundo o parágrafo $4^{\circ}$ do mesmo artigo, compete à ANS "definir a amplitude das coberturas, inclusive de transplantes e de procedimentos de alta complexidade". Porém, vale atentar que o parágrafo $4^{\circ}$ não pode ser lido e interpretado isoladamente, sem se levar em consideração o disposto no caput do artigo 10.

Em cumprimento a esse dispositivo legal, a ANS, no exercício de seu poder regulamentar, edita e revisa periodicamente o rol de coberturas obrigatórias, uma listagem de procedimentos e atendimentos que os planos de saúde devem, obrigatoriamente, cobrir.

A agência e o mercado defendem a exaustividade do referido rol, enquanto o entendimento do Poder Judiciário é diverso. O TJSP já possui entendimento pacífico e sumulado ${ }^{20}$ no sentido de que devem ser cobertos pelo plano de saúde todos os exames indicados pelo médico que sejam necessários para o tratamento de doenças cobertas, independentemente de previsão no rol da ANS.

Ainda com relação ao tema da exclusão de coberturas, o fato de a ANS não ter um processo contínuo de avaliação de seu rol de coberturas obrigatórias, implementando mudanças apenas a cada dois anos, a faz atuar a reboque das mudanças tecnológicas e procedimentais. No silêncio regulatório, o caminho é o Poder Judiciário.

Assim, a forma pela qual a ANS edita seu rol de coberturas obrigatórias e o interpreta como limite das obrigações legalmente exigíveis das operadoras, bem como a resistência da agência em aplicar, em sua rotina regulatória, os ditames do Código de Defesa do Consumidor, são fatores relevantes para justificar a exclusão de coberturas como tema mais recorrente nas decisões analisadas. Acresça-se a esse quadro a insistência das operadoras em negar a cobertura de procedimentos,

${ }^{20}$ Súmula n. 102 do TJSP: "Havendo expressa indicação médica, é abusiva a negativa de cobertura de custeio de tratamento sob o argumento da sua natureza experimental ou por não estar previsto no rol de procedimentos da ANS". 
em claro descumprimento à oferta de serviços amplos e irrestritos de saúde oferecidos aos consumidores no momento da contratação. Tudo isso faz com que os usuários busquem o Poder Judiciário ou o SUS para obter o tratamento de saúde necessário ${ }^{21}$.

Portanto, a restrição de coberturas na assistência médica suplementar é o principal tema no que se refere à judicialização, mesmo em contratos coletivos. Isso repercute na saúde e na vida da população usuária e nos custos administrativos das empresas de planos e seguros de saúde e também interfere no sistema público de saúde, pois procedimentos recusados na chamada saúde suplementar são absorvidos, em grande parte, pelo SUS.

\section{O direito à manutenção do aposentado no contrato coletivo e a fixação do valor devido de mensalidade}

O direito à manutenção do aposentado no contrato coletivo e a fixação do valor devido de mensalidade são temas materiais também frequentes nas decisões analisadas na pesquisa, sendo ambos discutidos, em conjunto ou separadamente, em 15\% dos acórdãos (608 acórdãos discutem o valor da mensalidade em caso de manutenção do aposentado no contrato coletivo, e 589 acórdãos discutem o direito do aposentado de ser mantido no contrato coletivo).

A Lei n. 9.656/1998, em seu artigo 31, garante ao aposentado beneficiário de um plano de saúde contratado coletivamente em decorrência de vínculo empregatício o direito de se manter no contrato coletivo nas mesmas condições de cobertura assistencial de que gozava quando da vigência do contrato de trabalho, desde que arque com o pagamento integral do plano.

O tempo pelo qual o aposentado poderá continuar como beneficiário do contrato coletivo varia: caso tenha contribuído por $10(\mathrm{dez})$ anos ou mais, poderá mantê-lo por toda a vida; se tiver contribuído por menos de 10 (dez) anos, o direito de se manter no plano é equivalente ao tempo de contribuição, sendo que a lei assegura o período mínimo de seis meses e máximo de 24 meses de permanência.

A lei também dispõe que o direito em questão não se aplica aos aposentados nos casos em que o plano de saúde é custeado integralmente pela empregadora, ainda que o beneficiário tenha pagado alguma quantia para utilização de serviços de assistência médica ou hospitalar. Porém, o TJSP tem forte entendimento no sentido da inaplicabilidade dessa disposição, por entender que o empregado contribuiu, mesmo que indiretamente, para o custeio do plano.

\footnotetext{
${ }^{21}$ BAHIA, L.; SIMMER, E.; OLIVEIRA, D. C. de. Cobertura de planos privados de saúde e doenças crônicas: notas sobre utilização de procedimentos de alto custo. Ciência \& Saúde Coletiva, v. 9, n. 4, p. 921-929, 2004. Disponível em: <http://www.scielo.br/pdf/csc/v9n4/a13v9n4.pdf>. http://dx.doi.org/10.1590/ S1413-81232004000400013.
} 
Para regulamentar o tema, a ANS editou a Resolução Normativa n. 279/201122. Algumas das regras previstas geram distorções e conflitos, a começar pela que permite a criação de carteiras exclusivas para ex-empregados. Isso significa que a empresa empregadora separa os funcionários ativos e inativos em grupos distintos, sendo todo o risco contratual calculado em separado. Todavia, a lei setorial nada diz a esse respeito nem permite tal segregação; apenas determina que o ex-empregado pode manter-se no mesmo plano de saúde em que estava quando empregado.

O TJSP já manifestou seu entendimento no sentido de que a criação de uma carteira exclusiva para inativos descumpre determinação legal, frisando que "a Norma Reguladora não pode restringir Direito" (Apelação n. 1082428-62.2013.8.26.0100).

Outra regra prevista pela $\mathrm{RN}$ n. 279/2011 que merece avaliação é o prazo de 30 dias para que o aposentado opte pela manutenção da condição de beneficiário, contado do comunicado do empregador de seu desligamento da empresa, que deve ser formalizado no ato da comunicação do aviso prévio, ou da comunicação da aposentadoria.

O TJSP tem entendimento no sentido de refutar o prazo criado pela ANS em sua regulação. Por outro lado, sustenta a aplicabilidade do instituto da supressio, a fim de que ao consumidor não se faculte eternamente o direito de optar por participar do plano coletivo da empresa em que trabalhou.

[...] Analisando-se a situação sob a ótica da operadora do plano, é demais exigir a falta de qualquer limitação temporal, pois ela teria que esperar indefinidamente pela opção dos aposentados, o que acarreta sensível insegurança jurídica. Portanto, ainda que não se aceite a aplicação do prazo de trinta dias, este deve servir, ao menos, como parâmetro.

[...] A existência de um prazo decadencial serviria exatamente a coibir tal tipo de situação, que revela conduta inconciliável com a boa-fé, a qual deve ser demonstrada em qualquer momento da relação contratual.

Nesse contexto, há de ser reconhecida a ocorrência da supressio, ou seja, a perda do direito pela inércia do apelado, já que a própria natureza do serviço, relacionada à prestação de serviços médico-hospitalares, exigia que fosse demonstrado maior empenho na busca pela continuidade da relação. (Apelação n. 0128814-75.2010.8.26.0100).

${ }^{22}$ AGÊNCIA NACIONAL DE SAÚDE SUPLEMENTAR - ANS. Resolução Normativa n. 279, de 25 de novembro de 2011. Dispõe sobre a regulamentação dos artigos 30 e 31 da Lei n 9.656, de 3 de junho de 1998, e revoga as Resoluções do CONSU ns 20 e 21, de 7 de abril de 1999. Disponível em: <http://www.ans.gov.br/component/ legislacao/?view=legislacao\&task=TextoLei\&format=raw\&id=MTg50A==>. Acesso em: 17 jun. 2018. 
Também cumpre analisar o artigo 26 da RN n. 279/2011, que traz hipóteses para extinção do direito previsto no artigo 31 da Lei n. 9.656/1998. Isso porque a norma regulamentar da ANS cria uma hipótese de extinção do direito de permanecer no contrato coletivo não prevista em lei: pelo cancelamento do contrato coletivo por parte do empregador. Nesse ponto, foram encontradas decisões na pesquisa que invalidam esta hipótese, nos seguintes termos:

Trazendo o dispositivo legal a imprescindível condição de que o beneficiário assumisse o pagamento integral das mensalidades do plano de saúde, estabeleceu-se, aí, um vínculo contratual autônomo com a empresa ré, tornando absolutamente irrelevante o fato de o contrato original ter sido cancelado pela contratante. (Apelação n. 1069751-97.2013.8.26.0100)

E não apenas o direito à manutenção do aposentado no contrato coletivo é questionado em juízo, como também o valor devido de mensalidade na hipótese de exercício desse direito.

A Lei n. 9.656/1998, no caput do artigo 31, determina apenas que o aposentado deve assumir o pagamento integral da mensalidade. $\mathrm{E}$ a $\mathrm{RN} \mathrm{n}$. 279/2011 estabelece duas situações: (a) se o ex-empregado for mantido no mesmo contrato coletivo, o valor da contraprestação pecuniária a ser paga por ele deverá corresponder ao valor integral estabelecido de seu custo por faixa etária, custo este que deverá ser apresentado aos beneficiários pela operadora no ato da contratação do plano de saúde e deve constar do contrato (art. 15); e (b) se o ex-empregado for transferido para a carteira exclusiva de inativos, será feito um novo contrato, que poderá prever condições de reajuste, preço e faixa etária diferenciadas das previstas no contrato coletivo que abrange os empregados ativos (art. 19).

Apesar de a Lei de Planos de Saúde mencionar apenas que os beneficiários aposentados têm direito à manutenção nas mesmas condições de cobertura assistencial, a adequada interpretação dessa norma leva à conclusão de que é necessária a manutenção do valor que era pago pelo plano de saúde. Nesse sentido, seguem trechos de decisões analisadas, a título exemplificativo:

Isso significa que se devem garantir ao aposentado TODAS as condições que possuía enquanto na ativa, mormente o valor da mensalidade do plano de saúde ofertado pela empregadora. $\mathrm{E}$ a razão do dispositivo legal é simples: se assim não for, ficará o empregado aposentado, quando mais precisa do plano de saúde pelo qual pagou por mais de década, impossibilitado de tê-lo em razão de tabelas cujo pagamento é incompatível com os ganhos da aposentadoria. (Apelação n. 101812539.2013.8.26.0100) 
Assim, no que se refere à regulação da questão de manter o aposentado no contrato coletivo e ao valor a ser pago por ele a título de mensalidade, é possível observar que a RN n. 279/2011 estabelece normas que exacerbam o poder regulamentar da ANS, gerando conflitos que acabam sendo levados à análise do Judiciário e que, não raro, rechaçam a regulação da ANS.

\section{Os reajustes por aumento de sinistralidade}

O reajuste por aumento de sinistralidade é outro tema discutido nas decisões analisadas na pesquisa e está presente em 6,8\% das demandas (275 acórdãos). Trata-se do reajuste aplicado por conta do aumento de utilização do plano, ou seja, incide quando o número de procedimentos (ou "sinistros") cobertos, em determinado período de tempo, foi maior do que o inicialmente previsto pela operadora.

O reajuste em questão é criação do mercado de planos de saúde. Para sua aplicação aos contratos coletivos, as operadoras costumam medir a sinistralidade considerando a carteira de beneficiários de cada contrato. Isso significa que não levam em consideração toda a sua base de consumidores, distribuindo o risco entre diferentes grupos etários e populacionais, e sim que optam por considerar um bloco pré-definido de usuários, geralmente contratantes em uma mesma época.

A Lei n. 9.656/1998 não trata especificamente do reajuste por aumento de sinistralidade. Apenas determina que o valor da mensalidade do plano de saúde e os critérios para seu reajuste devem estar claramente previstos no contrato.

A ANS, por meio de sua regulamentação, atuou a reboque de práticas consolidadas do mercado regulado. Com a RN n. 195/2009 ${ }^{23}$, a agência reguladora estabeleceu que nenhum contrato pode receber reajustes com periodicidade inferior a 12 meses, com exceção dos reajustes por mudança de faixa etária (art. 19). Por muitos anos, esse foi o único ponto regulatório de reajustes específicos de contratos coletivos que a agência adentrou.

$\mathrm{Na}$ prática, os contratos coletivos recebem anualmente um aumento, cujo cálculo tem forte componente de sinistralidade. Os custos considerados na composição do reajuste não são claramente discriminados, e até o momento a ANS não comprovou ter capacidade técnica e operacional para controle da veracidade dos dados apresentados pelas operadoras. Diferentemente dos contratos individuais, cujo

\footnotetext{
${ }^{23}$ AGÊNCIA NACIONAL DE SAÚDE SUPLEMENTAR - ANS. Resolução Normativa n. 195, de 14 de julho de 2009. Dispõe sobre a classificação e características dos planos privados de assistência à saúde, regulamenta a sua contratação, institui a orientação para contratação de planos privados de assistência à saúde e dá outras providências. Disponível em: <http://www.ans.gov.br/component/legislacao/?view=legislacao\&tas k=TextoLei\&format=raw\&id=MTQ10A==>. Acesso em: 17 jun. 2018.
} 
reajuste é definido pela agência, os contratos coletivos têm fixação livre de reajustes, havendo apenas o dever de informar à agência o percentual aplicado.

O resultado do tímido comportamento regulatório foi a explosão de reajustes elevadíssimos em planos de saúde coletivos, com fortes efeitos negativos para os consumidores. Exemplificativamente: se, em um contrato com cinco pessoas, uma delas fica grávida e tem uma gravidez que demanda cuidados, e outra é acometida por uma doença com tratamento custoso, como o câncer, o reajuste posterior a essas duas coberturas ("sinistros") seria muito alto, posto que o impacto nos custos do plano em razão dos dois tratamentos de saúde seria diluído apenas entre cinco pessoas.

Reativamente, diante do cenário de aplicação de altos reajustes por sinistralidade aos contratos coletivos com pequeno número de beneficiários (carteiras pequenas), a ANS editou a Resolução Normativa n. 309/2012 ${ }^{24}$, que determina que operadoras de planos de saúde devem agrupar seus contratos coletivos com menos de 30 vidas em um grupo único para aplicação do reajuste. A essa junção de carteiras deu-se o nome de pool de risco.

Apesar de somente admitir a necessidade de intervenção regulatória nos contratos coletivos com menos de 30 vidas, a ANS excetuou a aplicação da regra do pool de risco aos contratos exclusivos para inativos (ex-empregados demitidos ou aposentados) e aos contratos firmados antes da vigência ou não adaptados à Lei de Planos de Saúde.

O objetivo da norma foi diluir os efeitos do cálculo de sinistralidade em pequenos contratos. Assim, em tese, casos como o do contrato com cinco pessoas anteriormente apontado não mais ocorreriam. A regulamentação, ainda que parcial e tímida, não surtiu os efeitos esperados na judicialização.

Os consumidores questionam o reajuste por aumento de sinistralidade sob o fundamento de que se trata de uma criação do mercado de planos de saúde, não previsto pela Lei de Planos de Saúde. Também argumentam que sua aplicação significa claramente uma variação de preço unilateral pelas operadoras, vedada pelo artigo 51, incisos IV, X e XV, parágrafo $1^{\circ}$, incisos I a III do Código de Defesa do Consumidor.

Diferentemente das discussões sobre cobertura assistencial, o debate judicial sobre reajuste, por envolver diretamente tema econômico-financeiro, gera maior pluralidade nas decisões dos magistrados. Observou-se na pesquisa que há decisões que: (a) reconhecem a ilegalidade da cláusula contratual que

\footnotetext{
${ }^{24}$ AGÊNCIA NACIONAL DE SAÚDE SUPLEMENTAR - ANS. Resolução Normativa $n$. 309, de 24 de outubro de 2012. Dispõe sobre o agrupamento de contratos coletivos de planos privados de assistência à saúde para fins de cálculo e aplicação de reajuste. Disponível em: <http://www.ans.gov.br/component/legislacao/?vi ew=legislacao\&task=TextoLei\&format=raw\&id=Mjl4Mg==>. Acesso em: 17 jun. 2018.
} 
prevê o reajuste por aumento de sinistralidade ${ }^{25}$; (b) reconhecem a legalidade da cláusula, mas declaram a abusividade do reajuste específico aplicado ao caso $^{26}$; e (c) reconhecem a legalidade da cláusula e do reajuste específico aplicado ao caso $^{27}$.

Apesar de, pela análise dos dados obtidos com a pesquisa, não ser possível afirmar que o TJSP rechaça por completo o reajuste por sinistralidade, é possível concluir que este é um dos temas mais conflituosos, que inflam a judicialização da saúde suplementar e apontam para a deficiência da regulação da ANS relativa a essa questão.

${ }^{25}$ ILEGALIDADE DA CLÁUSULA DE REAJUSTE POR SINISTRALIDADE. A apelante justifica a aplicação do índice de 38,20\% (trinta e oito inteiros e vinte centésimos) para o reajuste, no aumento da sinistralidade ocorrido no contrato; entretanto, não faz qualquer prova acerca de suas alegações. Verifica-se a abusividade e lesividade do reajuste previsto como base na cláusula contratual 16.1 das condições gerais do contrato, inclusive, pela dificuldade de entendimento, pois traz fórmula inacessível [...] A fórmula de reajuste adotada ostenta evidente hermetismo e confere, à seguradora, a possibilidade de, sem qualquer controle do contratante, adotar os percentuais que desejar, obstada ou, ao menos, muito dificultada qualquer impugnação. Criou-se, em verdade, um verdadeiro malabarismo matemático. (Apelação n. 0072724-79.2012.8.26.0002)

${ }^{26}$ LEGALIDADE DA CLÁUSULA E ABUSIVIDADE DO REAJUSTE POR SINISTRALIDADE. Persiste, assim, a cláusula aqui transcrita, que por si só nada tem de ilegal ou abusiva, de modo que fica reconhecida sua validade. Contudo, embora seja possível, em tese, o reajuste ali previsto, deve a operadora do plano de saúde demonstrar o efetivo aumento na sinistralidade consistente na utilização dos serviços pelos usuários para além do limite de $70 \%$ e a existência de desequilíbrio financeiro no contrato. E nenhum documento foi trazido aos autos pela apelante. Dessa forma, não demonstrados os requisitos previstos no contrato, de fato é abusivo o reajuste realizado. (Apelação n. 0033285 29.2010.8.26.0003)

${ }^{27}$ LEGALIDADE DA CLÁUSULA E DO REAJUSTE POR SINISTRALIDADE. [...] No caso concreto, há que se ressaltar que se trata de contrato coletivo firmado entre duas pessoas jurídicas de direito privado, sem que se possa falar na vulnerabilidade de qualquer uma delas. Em primeiro lugar, nem de longe há a abusividade que se pretendeu ver na aplicação do índice utilizado para fator de correção das parcelas. Isto porque, o contrato firmado entre as partes estabelece, em sua cláusula décima sexta, item um, que "as partes estão cientes e concordam que a relação custo/receita deste contrato não pode ultrapassar a $70 \%$ (setenta por cento), tomando-se por base o valor bruto da fatura e das despesas médico/hospitalar cobertas como condição de segurança" (fls. 61). Note-se que, em carta enviada à requerente, a demandada informou-a de que haveria alteração de valores devido à utilização financeira do plano contratado (fls. 108), uma vez que o percentual previsto na cláusula supramencionada fora ultrapassado, atingindo 111,92\% (fls. 112). A ré, assim, apenas exerceu seu direito contratualmente previsto, justificando, mediante tabelas, a necessidade da majoração. Ademais, ao contrário do que alega a autora, não houve inovação na justificativa apresentada para o aumento das mensalidades, uma vez que nas duas cartas enviadas constou que o reajuste foi feito com base na utilização do plano por parte dos usuários (fls. 108 e 112). Na realidade, o que pretende a demandante é obter, no bojo de um contrato coletivo, a proteção conferida às apólices individuais, situação com a qual não se pode compadecer [...] Em segundo lugar, verifica-se que a cláusula que prevê a possibilidade de rescisão unilateral do contrato mediante aviso prévio por escrito de trinta dias também é valida, sendo inaplicável, por cuidar-se de contrato coletivo, o artigo 13 da Lei 9.656/98, pois o dispositivo é bem específico e protege apenas os planos privados de assistência à saúde. [...] Não há, tampouco, que se falar na declaração de nulidade das demais cláusulas mencionadas, uma vez que, tendo sido o contrato firmado entre duas pessoas jurídicas igualmente capazes, poderiam ter sido livremente discutidas e até mesmo dado ensejo para a não contratação. (Apelação n. 0214531 21.2011.8.26.0100) 


\section{0 reajuste por mudança de faixa etária}

O reajuste por mudança de faixa etária, quarto tema mais recorrente na presente pesquisa, foi discutido em $11,7 \%$ das decisões analisadas (475 acórdãos).

Trata-se do aumento imposto ao consumidor de plano de saúde com base na variação de sua idade. A Lei de Planos de Saúde, em seu artigo 15, previu a possibilidade de aplicação desse reajuste, desde que previsto em contrato, com a devida indicação das faixas etárias e dos percentuais de reajustes incidentes em cada uma delas. Mas também fez uma única ressalva: proibiu tal reajuste aos consumidores com mais de 60 anos, desde que participassem do plano de saúde há mais de 10 anos.

Antes de entrar em vigor a Lei n. 10.741/2003 ${ }^{28}$ (Estatuto do Idoso), vigoravam as regras trazidas pela Resolução n. 6/1998 do Conselho de Saúde Suplementar (Consu), que previa sete faixas etárias e autorizava o aumento total de até $500 \%$ entre elas. As faixas etárias estabelecidas eram: 0 a 17 anos; 18 a 29 anos; 30 a 39 anos; 40 a 49 anos; 50 a 59 anos; 60 a 69 anos; e 70 anos em diante.

Ocorre que diversas operadoras começaram a desvirtuar a regra, impondo aumentos abusivos nas últimas faixas etárias, levando à expulsão dos usuários com idade mais avançada do plano de saúde.

Diante dessa realidade e da entrada em vigor do Estatuto do Idoso - que textualmente proíbe a discriminação do idoso, pessoa com 60 anos ou mais, por meio da aplicação de reajustes por mudança de faixa etária (art. 15) -, a ANS editou a Resolução Normativa n. 63/2003 ${ }^{29}$, na qual manteve a possibilidade de reajustes de até $500 \%$ entre a primeira e a última faixa etária, mas mudou a padronização das mesmas. Previu-se a existência de dez faixas etárias, sendo vedado que o reajuste entre a sétima e a $10^{\text {a }}$ faixa ultrapasse o previsto entre a primeira e a sétima: 0 a 18 anos; 19 a 23 anos; 24 a 28 anos; 29 a 33 anos; 34 a 38 anos; 39 a 43 anos; 44 a 48 anos; 49 a 53 anos; 54 a 58 anos; e 59 anos ou mais.

O objetivo protetivo da Lei n. 10.741/2003, decorrente da proibição do reajuste por mudança de faixa etária para os idosos, perdeu seus efeitos por conta da regulamentação da ANS. Como a agência manteve os mesmos 500\% de reajuste entre a primeira e a última faixa etária, a única modificação foi a autorização da cobrança desse aumento todo mais cedo, distribuído entre as faixas até os 59 anos.

\footnotetext{
${ }^{28}$ BRASIL. Lei n. 10.741, de 01 de outubro de 2003. Dispõe sobre o Estatuto do Idoso e dá outras providências. Disponível em: <http://www.planalto.gov.br/ccivil_03/Leis/2003/I10.741.htm>. Acesso em: 17 jun. 2018. ${ }^{29}$ AGÊNCIA NACIONAL DE SAÚDE SUPLEMENTAR - ANS. Resolução Normativa n. 63, de 22 de dezembro de 2003. Define os limites a serem observados para adoção de variação de preço por faixa etária nos planos privados de assistência à saúde contratados a partir de $1^{\circ}$ de janeiro de 2004 . Disponível em: <http://www.ans.gov.br/component/legislacao/?view=legislacao\&task=TextoLei\&format=raw\&id=N zQ4>. Acesso em: 17 jun. 2018.
} 
Na pesquisa jurisprudencial, foram encontradas decisões que reconhecem que a aplicação de um índice alto de reajuste por mudança de faixa etária quando o consumidor completa 59 anos nada mais é que burla à proteção do Estatuto do Idoso:

Com efeito, verifico que o reajuste praticado de forma exorbitante aos 59 anos (128,55\%), como no caso sub judice, tem o intuito de burlar o Estatuto do Idoso, tendo em vista que este seria o último reajuste por faixa etária permitido, diante do disposto no artigo $15, \S 3^{\circ}$, do Estatuto do Idoso e da Súmula no 91 deste E. TJSP. (Apelação n. 1003895-23.2013.8.26.0704)

A ANS estabeleceu também que essas novas regras para os reajustes por faixa etária seriam aplicáveis apenas para os contratos de planos privados de assistência à saúde firmados a partir de $1^{\circ}$ de janeiro de 2004, ou seja, a partir da vigência do Estatuto do Idoso. Para os contratos firmados anteriormente, permaneceriam o pactuado entre as partes e a regra anterior.

Essa é outra questão que apareceu com destaque após a análise dos dados da pesquisa: a controvérsia com relação à aplicabilidade ou não da vedação de reajuste por faixa etária aos idosos aos contratos celebrados antes de $1^{\circ}$ de janeiro de 2004, data em que o Estatuto do Idoso entrou em vigor.

Apesar de a ANS ter emitido entendimento, em sua regulamentação, de que o Estatuto não se aplicaria aos contratos celebrados antes de sua entrada em vigor, a Justiça tem demonstrado posicionamento diverso.

O Superior Tribunal de Justiça vem consolidando jurisprudência na qual veda a aplicação de reajustes por mudança de faixa etária a qualquer idoso, independentemente da data de celebração do contrato. E, em consonância com a visão do STJ, o TJSP editou a Súmula n. $91^{30}$. Segundo o tribunal:

O Estatuto do Idoso é norma protetiva e deu efetividade ao art. 230 da Constituição da República, concretizando as garantias e os direitos fundamentais do idoso.

O direito ao envelhecimento, que foi disciplinado no art. $8^{\circ}$ do Estatuto em questão, está implícito na Constituição Federal, posto que tem relação direta com a dignidade da pessoa humana e com o solidarismo, que constituem, respectivamente, fundamento e princípio da República (art. $1^{\circ}$, inc. III e art. $3^{\circ}$, inc. I).

Dessa forma, e desde a Constituição Federal de 1988, qualquer disposição contratual ou legal que ofenda o direito ao pleno,

${ }^{30}$ Súmula n. 91: "Ainda que a avença tenha sido firmada antes da sua vigência, é descabido, nos termos do disposto no art. $15, \S 3^{\circ}$, do Estatuto do Idoso, o reajuste da mensalidade de plano de saúde por mudança de faixa etária". 
saudável, livre e digno envelhecimento da pessoa deve ser considerada abusiva, e portanto ilícita.

Daí por que a majoração da mensalidade do plano de saúde em decorrência única e exclusiva da mudança de faixa etária, alcançando o contratante com 60 anos ou mais, deve ser tida como não escrita, porquanto flagrante a ofensa aos princípios da Constituição Federal.

No caso dos autos, o reajuste foi implementado pela ré por conta única e exclusiva do aniversário de 60 anos do autor (fls. 18 e fls. 21/22). A implementação do reajuste apenas pela faixa etária do autor tem nítido caráter discriminatório. Ao reajustar excessivamente a mensalidade, a operadora do plano de saúde exclui do mercado médico-hospitalar privado o contrato ao idoso, que fica impedido de manter o plano diante dos altos valores cobrados. (Apelação n. 0159798-71.2012.8.26.0100)

De acordo com os dados colhidos na presente pesquisa (Tabela 3), 31,3\% das demandas analisadas certamente dizem respeito a usuários idosos e/ou aposentados, percentual equivalente ao de $27,6 \%$ de idosos na população coberta por planos.

Cabe esclarecer que é possível que este percentual seja, de fato, maior, já que em boa parte das decisões analisadas não há informação a respeito da idade e/ou situação de aposentadoria do beneficiário.

Com relação à aplicação de altos índices de reajuste, os usuários geralmente buscam a Justiça para questionar a aplicação de um índice muito elevado a título de reajuste por faixa etária, ainda que esteja previsto em contrato, baseando-se na vedação prevista no Código de Defesa do Consumidor de que o contrato estabeleça obrigação que seja excessivamente onerosa para o consumidor (art. 51, IV eX, $\$ 1^{\circ}$, II e III). Na pesquisa, foram identificadas tanto decisões favoráveis (Apelação n. 0192581-53.2011.8.26.0100) quanto desfavoráveis (Apelação n. 0003323-29.2013.8.26.0011) a essa tese.

Tabela 3. Presença de idosos e/ou aposentados nas decisões judiciais na Comarca de São Paulo do TJ/SP referentes a contratos de planos de saúde coletivos, 2013 e 2014

\begin{tabular}{lcc}
\hline O acórdão se refere a demanda de usuário idoso e/ou aposentado? & Total & $\%$ \\
\hline Não ou não informado & 2.790 & 68,74 \\
Sim & 1.269 & 31,26 \\
\hline
\end{tabular}

O fato de o reajuste por faixa etária figurar entre os cinco temas mais questionados pelos consumidores na Justiça, com base nos resultados da pesquisa, demonstra o descompasso entre a regulação da ANS, a realidade etária da população brasileira e a jurisprudência. 


\section{Conclusão}

A ANS optou por regular apenas timidamente os contratos coletivos de planos de saúde, assim como persistem os problemas estruturais de regulação do setor. Além disso, a agência é refratária à incorporação, em sua regulamentação, dos entendimentos jurisprudenciais e dos ditames do Código de Defesa do Consumidor.

A pesquisa jurisprudencial apresentada permitiu compreender os efeitos dessa escolha regulatória, que tem repercussões na intensa judicialização de conflitos entre consumidores de planos de saúde coletivos e operadoras que atuam no setor.

Os efeitos negativos evidenciados no estudo devem ser considerados visando à discussão sobre a eventual revisão da atual postura da ANS em relação à regulamentação dos contratos coletivos. Ao demonstrar as limitações e os problemas de planos de saúde coletivos levados aos tribunais, os resultados também contribuem para rechaçar as constantes investidas das empresas operadoras em favor da manutenção das regras sobre os contratos coletivos e mesmo da desregulamentação dos contratos individuais.

A partir do estudo, recomenda-se que a ANS reveja a regulamentação dos contratos coletivos, nos seguintes pontos: (i) efetiva incorporação das disposições do Código de Defesa do Consumidor a sua regulamentação; (ii) adequação da regulamentação sobre coberturas, principalmente acerca da abusividade e consequente ilegalidade de cláusulas contratuais de planos de saúde que excluem ou negam procedimentos não previstos no rol obrigatório; (iii) revisão da regulamentação dos artigos 30 e 31 da Lei n. 9.656/1998 e da Resolução Normativa n. 279/2011, a fim de vedar a criação de carteiras exclusivas para ex-empregados, readequar o prazo para que o aposentado possa optar pela manutenção da condição de beneficiário do contrato coletivo e excluir a extinção do direito previsto nos artigos 30 e 31 da Lei n. 9.656/1998 em caso de cancelamento do contrato coletivo pelo empregador; (iv) adequação da regulamentação de reajustes nos contratos coletivos, com o estabelecimento de novas regras de reajuste de planos de saúde, com transparência no método e nos dados utilizados e, principalmente, sua aplicação a todos os contratos, individuais e coletivos; além da vedação ao cálculo da sinistralidade, considerando também a capacidade futura do consumidor em arcar com a mensalidade; e (v) revisão da regulamentação de reajustes por faixa etária, principalmente a permissão do aumento de até $500 \%$ entre a primeira e a última faixa e a vedação de percentuais altos nas últimas faixas etárias, evitando burla ao Estatuto do Idoso.

A harmonização da regulação setorial à jurisprudência não só teria impactos sobre a redução da judicialização dos planos de saúde coletivos como traria garantias e melhorias à assistência à saúde da população atendida. 


\section{Referências}

ALVES, D. C.; BAHIA, L.; BARROSO, A. F. O papel da Justiça nos planos e seguros de saúde no Brasil. Cad. Saúde Pública, Rio de Janeiro, v. 25, n. 2, p. 279-290, fev. 2009. Disponível em: <http://www.scielo.br/pdf/csp/v25n2/06.pdf >. http://dx.doi.org/10.1590/ S0102-311X2009000200006.

ANDRADE, E. I. G. et al. A judicialização da saúde e a Política Nacional de Assistência Farmacêutica no Brasil: gestão da clínica e medicalização da justiça. Revista Médica de Minas Gerais, Belo Horizonte, v. 18, n. 4, Supl. 4, p. S46-S50, 2008. Disponível em: <http://rmmg. org/artigo/detalhes/1268>.

BAHIA, L. Mudanças e padrões das relações público-privado: seguros e planos de saúde no Brasil. 1999. Tese (Doutorado em Saúde Pública) - Faculdade de Medicina, Universidade Federal do Rio de Janeiro, 1999.

.; SIMMER, E.; OLIVEIRA, D. C. de. Cobertura de planos privados de saúde e doenças crônicas: notas sobre utilização de procedimentos de alto custo. Ciência \& Saúde Coletiva, v. 9, n. 4, p. 921-929, 2004. Disponível em: <http://www.scielo.br/pdf/csc/v9n4/a13v9n4.pdf>. http://dx.doi.org/10.1590/S1413-81232004000400013.

BRASIL. Ministério da Saúde. ANS. Caderno de Informação da Saúde Suplementar: Beneficiários, Operadoras e Planos, set. 2014. Rio de Janeiro: ANS, 2014.

. Caderno de Informação da Saúde Suplementar: Beneficiários, Operadoras e Planos, dez. 2016. Rio de Janeiro: ANS, 2017.

. Caderno de Informação da Saúde Suplementar: Beneficiários, Operadoras e Planos, dez. 2006. Rio de Janeiro: ANS, 2007.

CHIEFFI, A. L.; BARATA, R. B. Judicialização da política pública de assistência farmacêutica e equidade. Cadernos de Saúde Pública, Rio de Janeiro, v. 25, n.8, p.1839-1349, ago. 2009. Disponível em: <http://www.scielo.br/pdf/csp/v25n8/20.pdf>. http://dx.doi.org/10.1590/ S0102-311X2009000800020.

MARQUES, S. B.; DALLARI, S. G. Garantia do direito social à assistência farmacêutica no Estado de São Paulo. Revista Saúde Pública, São Paulo, v. 41, n. 1, p. 101-107, fev. 2007. Disponível em: <http://www.revistas.usp.br/rsp/article/viewFile/32199/34304>.

NOBRE, M. A. B. Da denominada "judicialização da saúde": pontos e contrapontos. In: NOBRE, M. A. B.; SILVA, R. A. D. (Coords.). O CNJ e os desafios da efetivação do Direito à Saúde. Belo Horizonte: Fórum, 2011. p. 353-366.

PEIXOTO, G. C. C. C.; SILVA, N. M. E. O acesso à justiça e os entraves jurisprudenciais criados para admissão do recurso especial. 2013. In: SOCIEDADE global e seus impactos sobre o estudo e a efetividade do direito na contemporaneidade. Florianópolis: FUNJAB, 2013. v. 1, p. 343-358. 
PEPE, V. L. E.; FIGUEIREDO, T. A.; SIMAS, L.; OSORIO-DE-CASTRO, C. G. S.; VENTURA, M. A judicialização da saúde e os novos desafios da gestão da assistência farmacêutica. Ciência \& Saúde Coletiva, Rio de Janeiro, v. 15, n. 5, p. 2405-2414, ago. 2010. Disponível em: <http://www.scielo.br/pdf/csc/v15n5/v15n5a15.pdf>. http://dx.doi. org/10.1590/S1413-81232010000500015.

.; VENTURA, M. (Orgs.). Manual indicadores de avaliação e monitoramento das demandas judiciais de medicamentos. Rio de Janeiro: Fundação Oswaldo Cruz, Escola Nacional de Saúde Pública Sergio Arouca, 2011. Disponível em: <http://www5.ensp.fiocruz. br/biblioteca/dados/txt_975659982.pdf>.

SALAZAR, A. L.; RODRIGUES, K.; NUNES JÚNIOR, V. S. A assistência privada à saúde: regulamentação, posição IDEC e reflexos no sistema público. In: ARANHA, Márcio Iorio (Org.). Direito sanitário e saúde pública. Brasília, 2003. v. 1, p. 333-362.

SANTOS, I. S. Evidência sobre o mix público-privado em países com cobertura duplicada: agravamento das iniquidades e da segmentação em sistemas nacionais de saúde. Ciência \& Saúde Coletiva, Rio de Janeiro, v. 16, n. 6, p. 2.743-2.752, 2011. Disponível em: <http://www. scielo.br/pdf/csc/v16n6/13.pdf>. http://dx.doi.org/10.1590/S1413-81232011000600013.

SCHEFFER, M. A exclusão de coberturas assistenciais nos planos de saúde privados. Saúde em Debate, Rio de Janeiro, v. 29, n. 71, p. 231-247, set./dez. 2005.

Coberturas assistenciais negadas pelos planos e seguros de saúde em ações julgadas pelo Tribunal de Justiça do Estado de São Paulo. Revista de Direito Sanitário, v. 14, p. 122-132, 2014. Disponível em: <http://www.revistas.usp.br/rdisan/article/view/56627>. http://dx.doi. org/10.11606/issn.2316-9044.v14i1p122-131.

SILVA, V. A. da; TERRAZAS, F. V. Claiming the Right to Health in Brazilian Courts: the exclusion of the already excluded? Law \& Social Inquiry, v. 36, p. 825-853, 2011. https://doi. org/10.1111/j.1747-4469.2011.01252.x.

SOUZA, M. H. S. C. et al. A intervenção do Poder Judiciário no setor de saúde suplementar tutelas antecipadas como instrumento de garantia da assistência à saúde no Brasil. Divulgação em Saúde para Debate, Rio de Janeiro, n. 37, p. 44-60, jan. 2007.

TERRAZAS, F.V. O Poder Judiciário como voz institucional dos pobres: o caso das demandas judiciais por medicamentos. 2008. Dissertação (Mestrado em Direito) Programa de Pós-Graduação em Direito, Faculdade de Direito. Universidade de São Paulo, São Paulo, 2008.

TRETTEL, D. B. Planos de saúde na visão do STJ e do STF. São Paulo: Verbatim, 2010.

Planos de saúde e envelhecimento populacional: um modelo viável? 2015. Tese (Doutorado em Direito) - Programa de Pós-Graduação em Direito, Faculdade de Direito. Universidade de São Paulo, São Paulo, 2015. 
VIANNA, L. W.k et al. A judicialização da política e das relações sociais no Brasil. 2. ed. Rio de Janeiro: Revan, 2014.

WANG, D. W. L.; VASCONCELOS, N. P. de; OLIVEIRA, V. E. de; TERRAZAS, F.V. Os impactos da judicialização da saúde no município de São Paulo: gasto público e organização federativa. Revista de Administração Pública, Rio de Janeiro, v. 48, n. 5, p. 1191-1206, set./out. 2014. Disponível em: <http://www.scielo.br/pdf/rap/v48n5/06.pdf>. http://dx.doi.org/10.1590/0034-76121666.

Daniela Batalha Trettel - Pós-Doutora pelo Programa de Medicina Preventiva na Faculdade de Medicina da Universidade de São Paulo (USP); doutora e mestre em Direitos Humanos pela Faculdade de Direito da USP. Defensora Pública do Estado de São Paulo. São Paulo/SP, Brasil.E-mail: danielabtrettel@yahoo.com.br

Juliana Ferreira Kozan - Mestranda do Programa de Medicina Preventiva na Faculdade de Medicina da Universidade de São Paulo; especialista em Direito Administrativo pela Faculdade Autônoma de Direito. Advogada. São Paulo/SP, Brasil. E-mail: julianafkozan@gmail.com

Mario César Scheffer - Professor Doutor do Departamento de Medicina Preventiva da Faculdade de Medicina da Universidade de São Paulo. São Paulo/SP, Brasil. E-mail: mscheffer@usp.br 